GUT MOTILITY

\title{
Role of cyclooxygenases 1 and 2 in the modulation of neuromuscular functions in the distal colon of humans and mice
}

\author{
M Fornai, C Blandizzi, R Colucci, L Antonioli, N Bernardini, C Segnani, B Baragatti, S Barogi, \\ P Berti, R Spisni, M Del Tacca
}

Gut 2005;54:608-616. doi: 10.1136/gut.2004.053322

See end of article for authors' affiliations

.....................

Correspondence to: Professor M Del Tacca, Divisione di Farmacologia e Chemioterapia, Dipartimento di

Oncologia, Trapianti e Nuove Tecnologie in Medicina, Università di Pisa, Via Roma, 55, 56126 Pisa, Italy: m.deltacca@med.unipi.it

Revised version received 3 November 2004 Accepted for publication 18 January 2005
(OX-2) may exert differential regulatory actions on Background: Cyclooxygenase isoforms (COX-1, COX-2) may
enteric motor functions under normal or pathological conditions.

Aims: To examine the occurrence and functions of COX-1 and COX-2 in the neuromuscular compartment of normal distal colon using human and murine tissue.

Methods: Gene expression (human, mouse), protein expression (human), gene deletion (mouse), and the effects of dual and isoform specific COX inhibitors on in vitro motility (human, mouse) were investigated. Results: Reverse transcription-polymerase chain reaction (RT-PCR) showed mRNA expression of COX-1 and COX-2 in human and wild-type mouse colonic muscle whereas only COX-2 or COX-1 was detected in COX-1 or COX-2 knockout animals. Immunohistochemistry localised both isoforms in neurones of myenteric ganglia, COX-1 in circular layer myocytes, and COX-2 in longitudinal muscle. Indomethacin (COX-1/COX-2 inhibitor), SC-560 (COX-1 inhibitor), or DFU (COX-2 inhibitor) enhanced atropine sensitive electrically induced contractions of human longitudinal muscle. The most prominent actions were recorded with indomethacin or SC-560 plus DFU. These results were confirmed under pharmacological blockade of non-cholinergic nerves. Atropine sensitive contractions evoked by carbachol in the presence of tetrodotoxin were enhanced by indomethacin or DFU but not by SC-560. In wild-type mice, contractile responses to electrical stimulation were enhanced by indomethacin, SC-560, or DFU. SC-560 potentiated electrically induced contractions in COX-2, but not COX-1, knockout mice. In contrast, DFU enhanced the contractions elicited by electrical stimuli in COX-1, but not in COX-2, knockout mice.

Conclusions: These results indicate that COX-1 and COX-2 are expressed in the neuromuscular compartment of normal human colon where they modulate cholinergic excitatory control of colonic motility at prejunctional and postjunctional sites, respectively.
$\mathrm{D}$ ifferent expression patterns have been reported for cyclooxygenase isoforms (COX-1, COX-2) throughout the gastrointestinal tract: COX-1 is constitutively expressed in the digestive tract of various species; COX-2 was initially regarded as inducible and detectable in the presence of pathological conditions but its constitutive expression in normal gastrointestinal tissues has been subsequently described. ${ }^{1-3}$ Cyclooxygenase products play pivotal roles in the regulation of digestive mucosal functions ${ }^{4}$ as well as in the pathophysiology of gut inflammatory, ulcerative, and neoplastic disorders. ${ }^{5-7}$ Accordingly, most studies have focused on mucosal expression of cyclooxygenase isoforms. ${ }^{89}$ However, prostaglandins also regulate the activity of myenteric neurones and the contractile functions of digestive smooth muscle, ${ }^{10}{ }^{11}$ and therefore the expression pattern of cyclooxygenase isoforms in gut neuromuscular compartments as well as their implications in the control of bowel motility deserve careful investigation. In particular, whether cyclooxygenase isoforms act mainly at the neuronal or muscular level, or both, to control digestive motor functions remains unclear.

Knowledge of the roles played by cyclooxygenases in the physiological control of gastrointestinal motility is currently limited. However, it has been shown that COX-1 and COX-2 are expressed in gastric neuromuscular tissues, and that the mechanical activities of gastric muscles are modulated by prostanoids originating from both isoforms. ${ }^{12}$ As far as pathological conditions are concerned, COX-2 seems implicated in postoperative ileus. ${ }^{13}{ }^{14}$ Roberts and colleagues ${ }^{15}$ also detected COX-2 in the myenteric plexus of patients with inflammatory bowel disease and proposed that this enzyme may play a role in the pathogenesis of motor disturbances associated with intestinal inflammation. Furthermore, COX-2 induction in jejunal muscularis externa is involved in mechanisms underlying persistent alterations of mouse bowel motility after recovery from intestinal infection. ${ }^{16}$

Based on this premise, the present study was designed to examine the occurrence and functions of COX-1 and COX-2 in tunica muscularis of the distal colon in human compared with murine tissue. We examined gene expression (human, mouse), protein expression (human), gene deletion (mouse), and the effects of dual and isoform specific COX inhibitors on the contractile activity of colonic smooth muscle (human, mouse).

\section{METHODS}

\section{Human tissue excision and preparation}

Colonic specimens were obtained from patients undergoing surgery for neoplastic conditions. Samples consisted of whole wall sections of distal colon from a macroscopically normal

Abbreviations: COX-1, cyclooxygenase 1; COX-2, cyclooxygenase 2; RT-PCR, reverse transcription-polymerase chain reaction; PBS, phosphate buffered saline; dNTP, deoxynucleotide triphosphate mixture; HRP, horseradish peroxidase; DAB, 3,3'-diaminobenzidine tetrahydrochloride; L-NAME, $\mathrm{N}^{\mathrm{\omega}}$-nitro-L-arginine methylester 
region taken at a distance of at least $5 \mathrm{~cm}$ from any visible lesion. Care was taken to verify the absence of alterations by histological examination. Only tissues excised intraoperatively within 60 minutes from skin incision were used. Portions of tissue were immediately snap frozen in liquid nitrogen and stored at $-80^{\circ} \mathrm{C}$ for subsequent reverse transcription-polymerase chain reaction (RT-PCR) analysis, or fixed in cold $4 \%$ paraformaldehyde, diluted in phosphate buffered saline (PBS), for routine histology or immunohistochemistry. The remaining parts of the colonic tissues were placed into preoxygenated Krebs solution and transported on ice to the laboratory. Longitudinal muscle strips of approximately $3 \mathrm{~mm}$ in width and $20 \mathrm{~mm}$ in length were prepared as previously described. ${ }^{17}$ To evaluate changes in cyclooxygenase expression throughout the experimental procedures, muscle strip fragments were stored at $-80^{\circ} \mathrm{C}$ at end of tissue preparation and at the end of the functional experiments. The experimental protocol was approved by the ethics committee of our university hospital.

\section{Animal care and tissue preparation}

Experiments were performed in 129/B6 mice with COX-1 $(-/-)$ and COX-2(-/-) genotypes (courtesy of Dr L. Ballou), ${ }^{18}$ and wild-type C57BL6 mice served as controls. Preliminary experiments confirmed that wild-type C57BL6 mice behave the same as COX-1(+/+) mice and therefore can be used as controls for COX-1(-/-) and COX-2(-l-) mice. Genotypes were confirmed by PCR. ${ }^{19}$ Animal care was in accordance with the European Community Council Directive 86-609, recognised by the Italian Government. The colon was removed and flushed with cold Krebs solution. Colonic fragments were excised, subjected to mucosa and submucosa removal by sharp dissection, snap frozen in liquid nitrogen, and stored at $-80^{\circ} \mathrm{C}$ for subsequent RT-PCR. The remaining part was used for recording contractile activity of longitudinal muscle.

\section{RT-PCR analysis}

Total RNA was isolated by Trizol (Life Technologies, Carlsbad, California, USA) and chloroform. RNA ( $1 \mu \mathrm{g})$ served as template for single strand cDNA synthesis in a reaction using $2 \mu \mathrm{l}$ random hexamers $(0.5 \mu \mathrm{g} / \mu \mathrm{l})$ with $200 \mathrm{U}$ MMLV-reverse transcriptase in manufacturer's buffer containing $500 \mu \mathrm{M}$ deoxynucleotide triphosphate mixture (dNTP) and $10 \mathrm{mM}$ dithiothreitol. PCR was performed by specific primers based on the nucleotide sequence of cloned COX-1 and COX-2 human or mouse genes (table 1). ${ }^{20}{ }^{21}$ PCR, consisting of $25 \mu \mathrm{l}$ of RT products, Taq polymerase $2.5 \mathrm{U}$, dNTP $100 \mu \mathrm{M}$, and primers $0.5 \mu \mathrm{M}$, was performed by a PCR-Express thermocycler (Hybaid, Ashford, UK), as reported in table 1. Untranscribed RNA was included in PCR reactions to verify the absence of genomic DNA. RT-PCR efficiency was evaluated by primers for human or mouse $\beta$-actin (table 1 ). Amplified products were separated by $1.5 \%$ agarose gel electrophoresis and stained with ethidium bromide. cDNA bands were visualised by UV light, quantitated by densitometric analysis with NIH Image program (Scion Corporation, Frederick, Maryland, USA), and normalised to $\beta$-actin.

\section{Immunohistochemical analysis}

Fixed specimens were paraffin embedded and sections $(8 \mu \mathrm{m})$ were processed for haematoxylin-eosin staining or immunohistochemistry. In the latter case, as reported by Bernardini and colleagues, ${ }^{22}$ sections were sequentially exposed to: hydrogen peroxide $\left(1 \% \mathrm{H}_{2} \mathrm{O}_{2}\right.$ in methanol), proteinase $\mathrm{K}(0.05 \mathrm{mg} / \mathrm{ml}$ in PBS), normal swine serum ( $1: 20$ in PBS), and primary antibody ( $1: 100$ in PBS containing $0.1 \%$ bovine serum albumin and $0.1 \%$ sodium azide, overnight at $4^{\circ} \mathrm{C}$ ). Anti-COX-1 or anti-COX-2 antibodies were used. Myenteric neurones were detected on serial sections by antineurofilament antibody. Immunoreaction was detected by sequential use of biotinylated antigoat/rabbit immunoglobulins, streptavidin labelled with horseradish peroxidase (HRP), and 3,3'-diaminobenzidine (DAB $1 \mathrm{mg} / \mathrm{ml}$ in Tris buffer containing $0.02 \% \mathrm{H}_{2} \mathrm{O}_{2}$ ). Specimens were then counterstained with haematoxylin. To verify the specificity of immunohistochemical detections, non-immune serum or preadsorbed antisera were applied on serial sections. Briefly, COX-1 and COX-2 antisera were preadsorbed with specific COX-1 and COX-2 blocking peptides, respectively, at five times the antibody concentration, overnight at $4^{\circ} \mathrm{C}$. Endogenous peroxidases and avidin binding activity were tested by incubation of slides with $\mathrm{DAB}$ alone or streptavidin-HRP complex plus DAB.

\section{Recording of longitudinal muscle contractile activity}

Motor activity of colonic muscle was recorded as previously described. ${ }^{17}$ Preparations were set up in $10 \mathrm{ml}$ organ baths containing Krebs solution at $37^{\circ} \mathrm{C}$, bubbled with $95 \% \mathrm{O}_{2}+5 \%$ $\mathrm{CO}_{2}$. Preparations were connected to isotonic transducers (Basile, Comerio, Italy) under constant load ( 1 and $0.5 \mathrm{~g}$ for human and mouse, respectively) and allowed to equilibrate for 30 minutes. Longitudinal muscle activity was recorded by polygraph (Basile, Comerio, Italy). Transmural electrical stimulation was delivered by a BM-ST6 stimulator

Table 1 Primers used for reverse transcription-polymerase chain reaction analysis of cyclooxygenase (COX) isoforms and $\beta$-actin mRNA expression in human and mouse colonic tissues

\begin{tabular}{|c|c|c|}
\hline Gene & Nucleotide sequence & $\begin{array}{l}\text { Product size } \\
\text { (bp) }\end{array}$ \\
\hline Human COX-1 & $\begin{array}{l}\text { S: 5'-TGC CCA GCT CCT GGC CCG CCG CTT-3' } \\
\text { A: 5'-GTG CAT CAA CAC AGG CGC CTC TTC-3' }\end{array}$ & 301 \\
\hline Human COX-2 & $\begin{array}{l}\text { S: 5'-TTC AAA TGA GAT TGT GGG AAA ATT GCT-3' } \\
\text { A: 5'-AGA TCA TCT CTG CCT GAG TAT CTT-3' }\end{array}$ & 305 \\
\hline Mouse COX-1 & $\begin{array}{l}\text { S: 5'-AGG AGA TGG CTG CTG AGT TGG-3' } \\
\text { A: 5'-AAT CTG ACT TTC TGA GTT GCC-3' }\end{array}$ & 602 \\
\hline Mouse COX-2 & $\begin{array}{l}\text { S: 5'-ACA CAC TCT ATC ACT GGC ACC-3' } \\
\text { A: 5'-TTC AGG GAG AAG CGT TTG C-3' }\end{array}$ & 274 \\
\hline Human and mouse $\beta$-actin & $\begin{array}{l}\text { S: 5'-TCA TGA AGT GTG ACG TTG ACA TCC GT-3"' } \\
\text { A: 5'-CT AGA AGC ATT TGC GGT GCA CGA TG-3' }\end{array}$ & 286 \\
\hline
\end{tabular}

After three minutes of denaturation at $94^{\circ} \mathrm{C}, \mathrm{PCR}$ was performed as follows: 30 cycles of denaturation at $94^{\circ} \mathrm{C}$ (one minute), annealing at $50^{\circ} \mathrm{C}\left(1.5\right.$ minutes), extension at $72^{\circ} \mathrm{C}$ (two minutes), final extension at $72^{\circ} \mathrm{C}$ for 10 minutes (human COX-1, COX-2); 32 cycles of denaturation at $94^{\circ} \mathrm{C}\left(15\right.$ seconds), annealing at $60^{\circ} \mathrm{C}(15$ seconds), extension at $72^{\circ} \mathrm{C}$ (one minute), final extension at $72^{\circ} \mathrm{C}$ for seven minutes (mouse COX-1); 35 cycles of denaturation at $94^{\circ} \mathrm{C}\left(15\right.$ seconds), annealing at $55^{\circ} \mathrm{C}\left(15\right.$ seconds), extension at $72^{\circ} \mathrm{C}$ (one minute), final extension at $72^{\circ} \mathrm{C}$ for seven minutes (mouse COX-2). S, sense; $\mathrm{A}$, antisense. 
(Biomedica Mangoni, Pisa, Italy). Stimuli were applied as 10 second single trains of suprathreshold square wave pulses $(0.5 \mathrm{~ms}, 30 \mathrm{~mA})$ at $10 \mathrm{~Hz}$. Each preparation was repeatedly challenged with electrical stimulations, and experiments started when reproducible responses were obtained (usually after 2-3 stimulations).

In the first series, human or mouse preparations were exposed to the cyclooxygenase inhibitors, indomethacin $(1 \mu \mathrm{M})$, SC-560 $(0.1 \mu \mathrm{M})$, or DFU $(1 \mu \mathrm{M})$, for 30 minutes before electrical stimulation. Preparations were incubated with test drugs along two 15 minute consecutive periods with an intervening washing. Drug concentrations were selected on the basis of previous studies. ${ }^{23} 24$ The second set was designed to assay cyclooxygenase inhibitors on responses elicited by electrical stimulation directed selectively at cholinergic innervation. Human preparations were maintained in Krebs solution containing guanethidine (adrenergic blocker $10 \mu \mathrm{M}$ ), $\mathrm{N}^{\omega}$-nitro-L-arginine methylester (L-NAME, nitric oxide synthase inhibitor, $100 \mu \mathrm{M})$, L-732,138 ( $\mathrm{NK}_{1}$ receptor antagonist $10 \mu \mathrm{M})$, GR-159897 $\left(\mathrm{NK}_{2}\right.$ receptor antagonist $1 \mu \mathrm{M})$, and SB-218795 $\left(\mathrm{NK}_{3}\right.$ receptor antagonist $1 \mu \mathrm{M})$, to prevent non-cholinergic responses. ${ }^{25}$ Incubation of strips with cyclooxygenase inhibitors before challenge with electrical stimulation was performed as reported above. In the last series, cyclooxygenase inhibitors were assayed on cholinergic responses of human preparations elicited by extrinsic activation of muscarinic receptors on smooth muscle cells. Preparations were maintained in Krebs solution containing tetrodotoxin $(1 \mu \mathrm{M})$, and stimulated twice with carbachol (muscarinic receptor agonist $1 \mu \mathrm{M}$ ). The first stimulation was applied in the absence of other drugs while the second was applied after 30 minutes of incubation with cyclooxygenase inhibitors, as reported above. In a subset of experiments on human preparations, cyclooxygenase inhibitors were assayed on contractions evoked by exogenous histamine $(1 \mu \mathrm{M})$ in the presence of tetrodotoxin. Additional experiments, designed to test the effects of cyclooxygenase inhibitors on contractions elicited by carbachol in colonic preparations of COX-2 deficient mice, were carried out in accordance with the protocol reported above for human tissues.

\section{Drugs and reagents}

Indomethacin, SC-560 (5-(4-clorophenyl)-1-(4-metoxyphenyl)-3-trifluoromethyl-pirazole), atropine sulphate, L-NAME, carbachol hydrochloride, histamine diphosphate, and guanethidine were supplied by Sigma Chemical (St Louis, Missouri, USA); DFU (3-(3-fluorophenyl)-4-(4-methanesulfonyl)-5,5-dimethyl-5H-furan-2-one) was kindly provided by Merck Research Laboratories (Rahway, New Jersey, USA); L-732,138, GR-159897, SB-218795, and tetrodotoxin by Tocris Cookson (Bristol, UK); random hexamers, MMLVreverse transcriptase, Taq polymerase, and dNTP mixture by Promega (Madison, Wisconsin, USA); proteinase $\mathrm{K}$ by Boerhinger-Mannheim (Mannheim, Germany); goat antiCOX-1 polyclonal antibody (raised against a peptide mapping at the carboxy terminus of COX-1 of human origin; cod. No. Sc-1752), anti-COX-2 polyclonal antibody (raised against a peptide mapping at the amino terminus of COX-2 of rat origin, and cross-reacting with COX-2 of human origin in immunohistochemical assays on paraffin embedded tissues; cod. No. Sc-1746), COX-1 (cod. No. Sc-1752p), and COX-2 (cod. No. Sc-1746p) blocking peptides by Santa Cruz Biotechnology (Santa Cruz, California, USA); rabbit antineurofilament polyclonal antibody by Chemicon (Temecula, California, USA); and antigoat and antirabbit biotinylated immunoglobulins, horseradish peroxidase-streptavidin complex, and 3,3'-diaminobenzidine tetrahydrochloride by Dakopatts (Milan, Italy). Cyclooxygenase inhibitors were
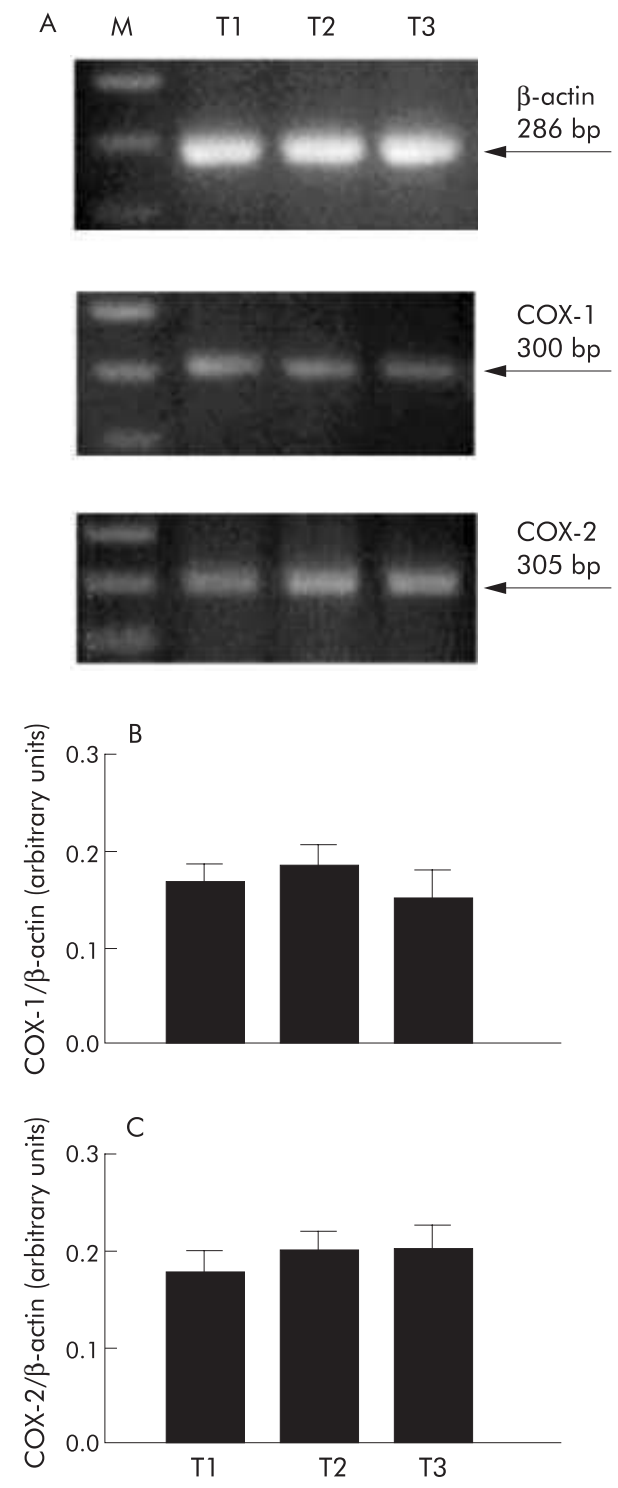

Figure 1 Reverse transcription-polymerase chain reaction analysis of cyclooxygenase 1 (COX-1), cyclooxygenase 2 (COX-2), and $\beta$-actin mRNA in the tunica muscularis of human distal colon at different times in the experimental sequence. $\mathrm{T1}$, time of excision in the surgery room; T2, end of longitudinal muscle strip preparation; and T3, end of pharmacological experiments with cyclooxygenase inhibitors. (A) Three representative agarose gels, referring to amplification of COX-1, COX-2, and $\beta$-actin cDNAs. $(B, C)$ Column graphs referring to densitometric analysis of COX-1 and COX-2 cDNA bands normalised to expression of $\beta$-actin. $M$, size markers. Each column represents the mean value (SEM) obtained from four separate experiments.

dissolved in dimethylsulphoxide and further dilutions were made with saline solution. Dimethylsulphoxide concentration in the organ bath never exceeded $0.5 \%$. At this concentration, dimethylsulphoxide alone did not affect resting tone, spontaneous contractile activity, or evoked motor responses in either human or mouse colonic preparations.

\section{Statistical analysis}

Results are expressed as per cent values of control data and given as mean (SEM). The significance of differences was evaluated on raw data, prior to percentage normalisation, by one way analysis of variance (ANOVA) followed by the Student-Newman-Keuls test. A p value $<0.05$ was 


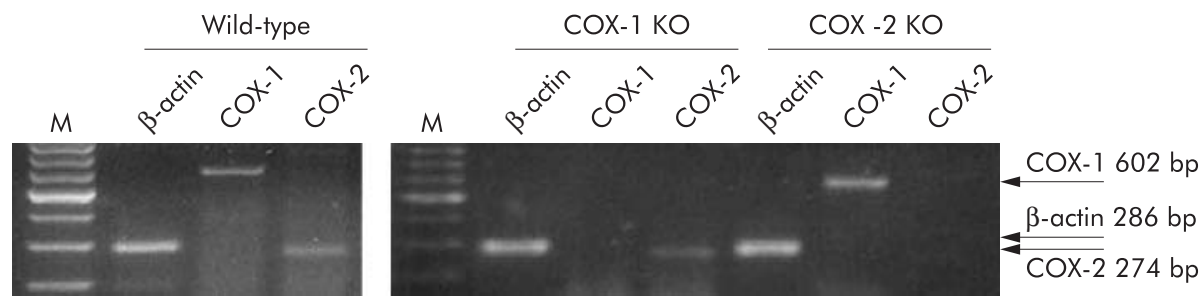

Figure 2 Reverse transcription-polymerase chain reaction analysis of cyclooxygenase 1 (COX-1), cyclooxygenase 2 (COX-2), and $\beta$-actin mRNA in the muscular layer of distal colon obtained from wild-type (WT), COX-1 knockout (COX-1 KO), or COX-2 knockout (COX-2 KO) mice. M, size markers.

considered significant. Colonic preparations included in each test group were obtained from distinct patients or animals, and therefore the number of experiments also refers to the number of patients or animals assigned to each group. Calculations were performed by commercial software (GraphPad Prism, version 3.0; GraphPad Software Inc., San Diego, California, USA).

\section{RESULTS}

\section{RT-PCR analysis}

RT-PCR analysis revealed expression of both COX-1 and COX-2 in the neuromuscular layer of the human colon. Densitometric analysis of cDNA bands did not show appreciable changes in expression of either cyclooxygenase isoform at different experimental times (fig 1). RT-PCR analysis of tissues from wild-type animals showed expression of both COX-1 and COX-2 mRNA. Furthermore, as expected, in tissues from COX-1 or COX-2 knockout mice, RT-PCR revealed only expression of COX-2 or COX-1 mRNA, respectively (fig 2 ).

\section{Immunohistochemical analysis}

In the neuromuscular compartment of the human colon, immunostaining for COX-1 was detected in myenteric ganglia at the level of neuronal cells. Cell specificity was confirmed by antineurofilament immunoreactivity on serial sections (fig 3A, B). COX-1 immunoreaction was localised within neuronal soma and distributed throughout the cytoplasm. COX-1 was also observed in cells of both circular and longitudinal muscle layers, particularly localised within the cytoplasm of circular layer myocytes (fig 3B). Different localisations were observed with anti-COX-2 antibody. Within myenteric ganglia weak COX-2 immunoreactivity was evident in the cytoplasm of neurones (fig 3C), and COX-2 was also detected throughout the cytoplasm of longitudinal smooth muscle cells (fig 3C).

\section{Effects of cyclooxygenase inhibitors on longitudinal smooth muscle activity \\ Studies on human colon}

During equilibration, most muscle preparations displayed rapid spontaneous activity which was low in amplitude and generally stable throughout the experiment. Electrically evoked responses consisted of phasic contractions (6.1 (0.7) $\mathrm{mm} ; \mathrm{n}=8$ ) followed, in most cases, by after contractions of variable amplitude. Atropine ( $1 \mu \mathrm{M})$ abolished initial phasic contractions or converted them into relaxations, and only after contractions became evident (fig 4A, B). Tetrodotoxin $(1 \mu \mathrm{M})$ abolished electrically induced responses $(-94 \%)$. Indomethacin $(1 \mu \mathrm{M})$ did not usually affect resting muscle tone, although transient and moderate reductions (up to $0.6-1.1 \mathrm{~mm}$ ) were recorded in less than $20 \%$ of colonic preparations. Furthermore, no changes in resting tone were observed on incubation of muscle strips with SC-560 $(0.1 \mu \mathrm{M})$ or DFU $(1 \mu \mathrm{M})$. Under these conditions, cyclooxygenase inhibitors did not affect spontaneous contractile activity while they enhanced the responses elicited by electrical stimulation. The most prominent effects were recorded with indomethacin ( $1 \mu \mathrm{M}$; $+42 \%$; fig $4 \mathrm{C}, 5 \mathrm{~A})$ while

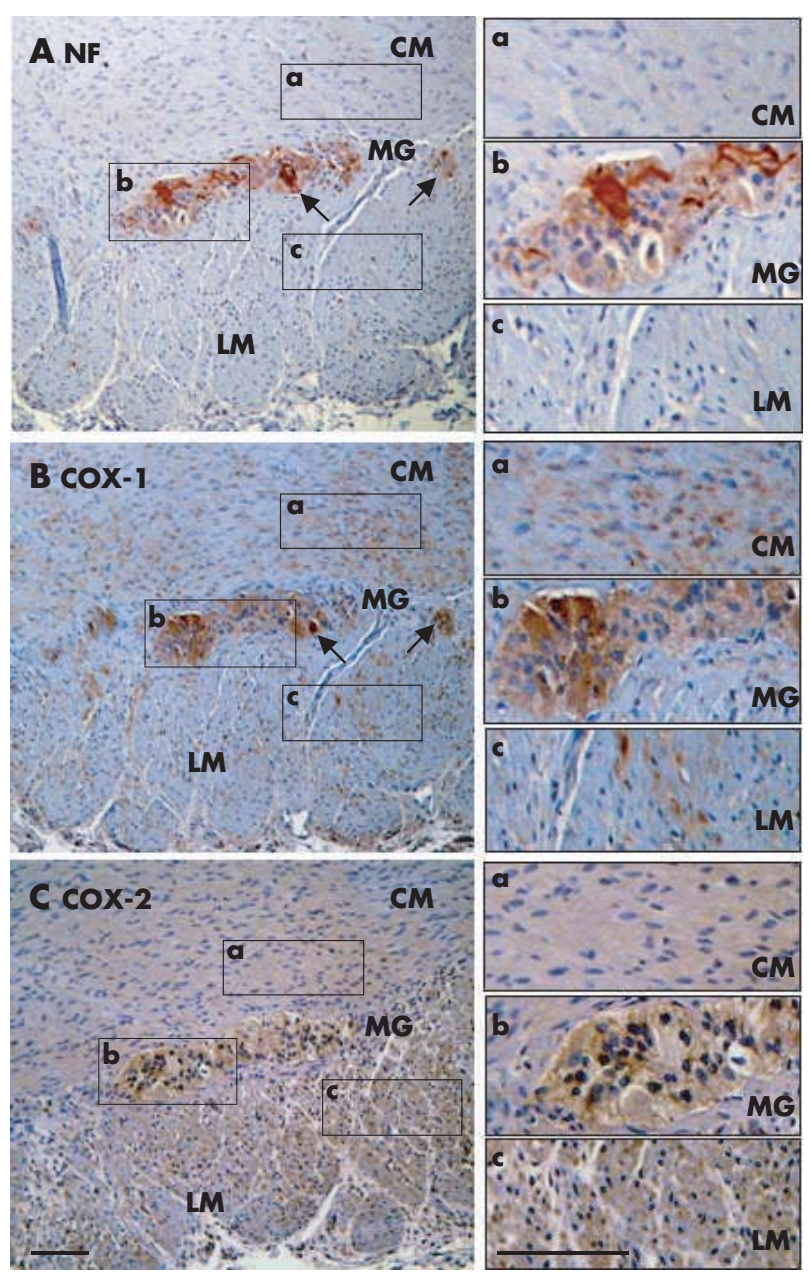

Figure 3 Immunohistochemical staining for antineurofilament (NF) (A), cyclooxygenase $1(\mathrm{COX}-1)(\mathrm{B})$, and cyclooxygenase $2(\mathrm{COX}-2)(\mathrm{C})$ in circular muscle (CM), myenteric ganglia (MG), and longitudinal muscle (LM) of normal human colon serial sections. Right panels display higher magnifications of (A), (B), and (C) micrographs, corresponding to boxed areas in circular muscle (a), myenteric ganglia (b), and longitudinal muscle (c). (A) Neurones of myenteric ganglia were strongly immunostained for neurofilament (arrows and (b) boxed area). (B) Specific COX-1 immunostaining was detected in neurones of myenteric ganglia (arrows and (b) boxed area) and in muscle layers ((a) and (c) boxed areas), mainly within cells of circular muscle. (C) Weak COX-2 signal within myenteric neurones ((b) boxed area) and appreciable COX-2 positivity in longitudinal muscle ((c) boxed area) were evident. Scale bars $100 \mu \mathrm{m}$. 


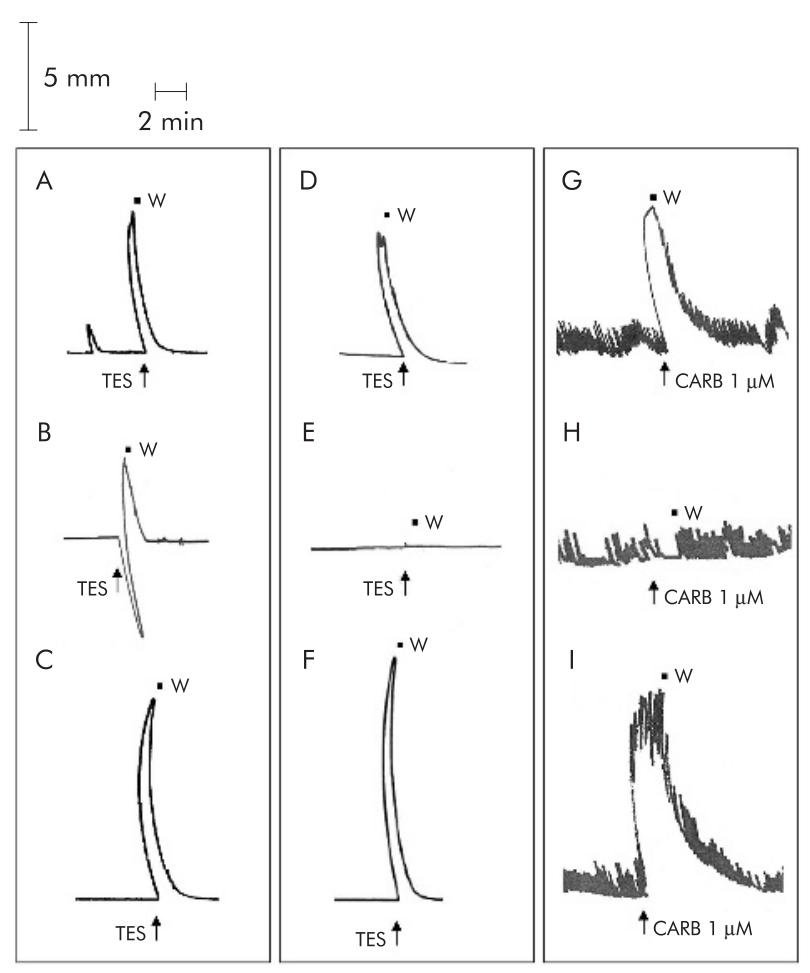

Figure 4 Isolated human distal colon. Left panel: representative trace recordings showing the contractile responses of a longitudinal muscle preparation incubated in standard medium and subjected to application of transmural electrical stimulation (TES $0.5 \mathrm{~ms}, 10 \mathrm{~Hz}, 10$ seconds), alone $(A)$ or in the presence of atropine $1 \mu \mathrm{M}(\mathrm{B})$ or indomethacin $1 \mu \mathrm{M}$ (C). Middle panel: representative trace recordings showing the contractile responses of a longitudinal muscle preparation incubated in medium containing guanethidine $10 \mu \mathrm{M}, \mathrm{N}^{\omega}$-nitro-l-arginine methylester $100 \mu \mathrm{M}, \mathrm{L}-732,13810 \mu \mathrm{M}, \mathrm{GR}-1598971 \mu \mathrm{M}$, and SB-218795 $1 \mu \mathrm{M}$ and subjected to TES, alone (D) or in the presence of atropine $1 \mu \mathrm{M}(\mathrm{E})$ or indomethacin $1 \mu \mathrm{M}(\mathrm{F})$. Right panel: representative trace recordings showing the effects of carbachol (CARB $1 \mu M$ ), alone $(G)$ or in the presence of atropine $1 \mu \mathrm{M}(\mathrm{H})$ or indomethacin $1 \mu \mathrm{M}(\mathrm{I})$, on the contractile activity of a longitudinal muscle preparation incubated in medium containing tetrodotoxin $1 \mu \mathrm{M}$. Motor responses displayed in each panel were recorded from the same muscle strip. The three colonic preparations were retrieved from the same patient. W, washing.

SC-560 $(0.1 \mu \mathrm{M})$ or DFU $(1 \mu \mathrm{M})$ were less effective $(+30 \%$ and $+21 \%$; fig $5 \mathrm{~A}$ ). After incubation with SC-560 plus DFU, electrical stimulation induced motor responses with an amplitude $(+46 \%)$ comparable with that observed with indomethacin (fig 5A).

In the presence of guanethidine, L-NAME, and NK receptor antagonists, electrical stimulation evoked phasic contractions (5.7 (0.8) mm; $\mathrm{n}=7$ ) which were abolished, or markedly reduced, by atropine $1 \mu \mathrm{M}$ (fig4D, E). Likewise, they were suppressed by tetrodotoxin ( $1 \mu \mathrm{M} ;-97 \%)$ while hexamethonium $(10 \mu \mathrm{M})$ had no effect $(-6 \%)$. Under these conditions, indomethacin $(1 \mu \mathrm{M})$ enhanced cholinergic contractile responses to electrical stimulation $(+109 \%$; fig $4 \mathrm{~F}, 5 \mathrm{~B})$. SC-560 $(0.1 \mu \mathrm{M})$ or DFU $(1 \mu \mathrm{M})$ mimicked this effect although they were less effective $(+69 \%$ and $+51 \%$; fig $5 \mathrm{~B})$. Incubation with SC-560 plus DFU was followed by potentiation of electrically induced contractions $(+101 \%)$ similar to that achieved with indomethacin (fig 5B).

Exposure of preparations to carbachol $(1 \mu \mathrm{M})$ resulted in atropine sensitive contractions (fig 4G, H). Carbachol induced contractions (6.3 ( 1$) \mathrm{mm} ; \mathrm{n}=8$ ) were enhanced to a similar extent by indomethacin $(1 \mu \mathrm{M})$ or DFU $(1 \mu \mathrm{M})$ $(+50 \%$ and $+43 \%$, respectively) while SC-560 $(0.1 \mu \mathrm{M})$ had no

\begin{tabular}{l}
$\square$ Control $\quad \square$ Indomethacin $1 \mu \mathrm{M}$ \\
$\square$ SC-560 0.1 $\mu \mathrm{M} \quad \square$ DFU $1 \mu \mathrm{M}$ \\
$\square$ SC-560 0.1 $\mu \mathrm{M}+$ DFU $1 \mu \mathrm{M}$ \\
\hline
\end{tabular}
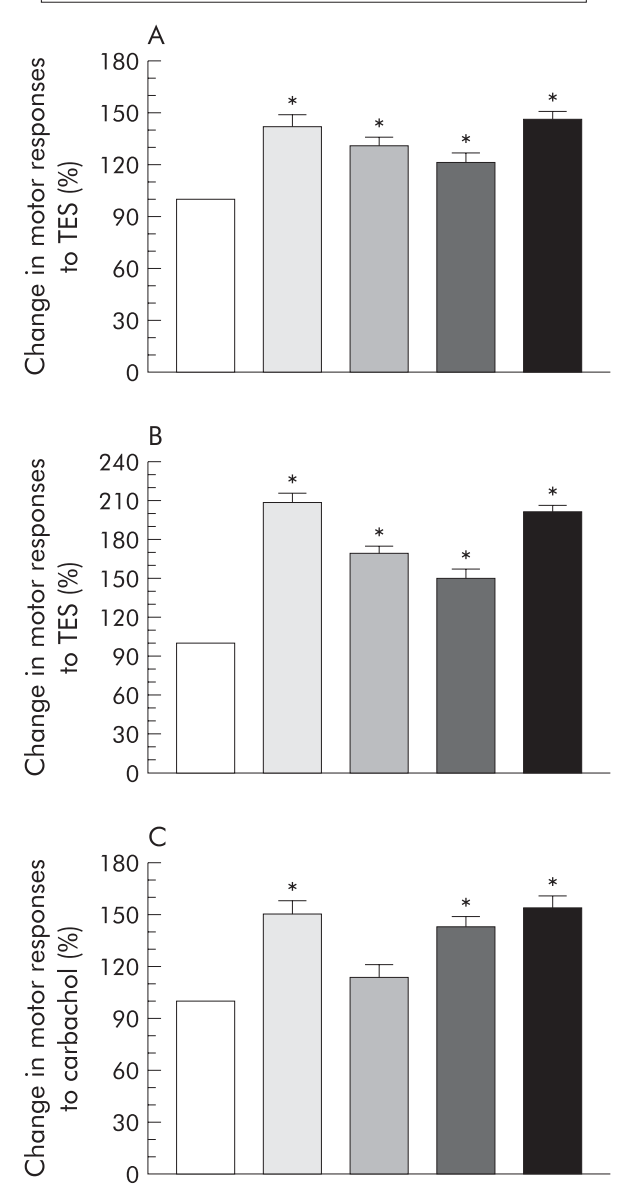

Figure 5 Isolated human distal colon. Effects of indomethacin $1 \mu \mathrm{M}$, SC-560 0.1 $\mu \mathrm{M}$, DFU $1 \mu \mathrm{M}$, and SC-560 plus DFU on the contractile responses of longitudinal muscle preparations under the following conditions: $(A)$ incubation in standard medium and application of transmural electrical stimulation (TES $0.5 \mathrm{~ms}, 10 \mathrm{~Hz}, 10$ seconds); (B) incubation in medium containing guanethidine $10 \mu \mathrm{M}, \mathrm{N}^{\omega}$-nitro- $\mathrm{L}-$ arginine methylester $100 \mu \mathrm{M}, \mathrm{L}-732,13810 \mu \mathrm{M}, \mathrm{GR}-1598971 \mu \mathrm{M}$, SB-218795 $1 \mu \mathrm{M}$, and application of TES; (C) incubation in medium containing tetrodotoxin $1 \mu \mathrm{M}$ and stimulation with carbachol $1 \mu \mathrm{M}$. Each column represents the mean (SEM) value obtained from 6-8 experiments. ${ }^{*} p<0.05$ compared with the control value.

effect (fig 4I, 5C). Following incubation with SC-560 plus DFU, carbachol elicited contractile responses (+53\%) not different from those recorded with DFU alone (fig 5C). Under the same conditions, histamine $(1 \mu \mathrm{M})$ elicited contractions which were insensitive to indomethacin, SC-560, DFU, or SC-560 plus DFU.

\section{Studies on isolated mouse colon}

During equilibration, colonic preparations from wild-type or knockout animals developed spontaneous activity which remained nearly stable throughout the experiment. In most cases, electrical stimulation elicited motor responses consisting of moderate relaxations followed by after contractions. However, in several preparations from COX-1 knockout mice, the relaxant response was less evident, or even missing, and electrical stimulation evoked contractions with variable superimposed after contractions (fig 6A-C). Mean amplitudes of contractile responses elicited by electrical 
stimulation of colonic preparations from wild-type, COX-1, and COX-2 knockout mice were $3.2(0.6) \mathrm{mm}(\mathrm{n}=7), 3.5$ (0.7) $\mathrm{mm}(\mathrm{n}=7)$, and $3.7(0.9) \mathrm{mm}(\mathrm{n}=6)$, respectively. In the presence of atropine ( $1 \mu \mathrm{M})$, preparations from wild-type or transgenic animals responded to electrical stimuli with marked enhancement of relaxation followed by variable after contractions (fig 6D-F).

No significant variations in resting muscle tone were detected when applying indomethacin, SC-560, or DFU to colonic preparations from wild-type as well as COX-1 or COX-2 knockout mice. In tissues from wild-type mice, indomethacin $(1 \mu \mathrm{M})$ enhanced electrically evoked contractions $(+74 \%)$ (fig 7A). SC-560 $(0.1 \mu \mathrm{M})$ or DFU $(1 \mu \mathrm{M})$ also enhanced the evoked responses although to a lesser extent ( $+40 \%$ and $+49 \%$, respectively) (fig $6 \mathrm{G}, \mathrm{J}, \mathrm{M}$, P; fig 7A). Coincubation with SC-560 plus DFU enhanced the evoked motor activity $(+67 \%)$, hence duplicating indomethacin action (fig 7A). In COX-1 knockout mice, the contractile response to electrical stimuli was potentiated by indomethacin or DFU $(+34 \%$ and $+29 \%)$ while SC-560 had no effect (fig $6 \mathrm{H}, \mathrm{K}, \mathrm{N}$, Q; fig 7B). By contrast, in COX-2 knockout animals, DFU did not modify electrically induced contractions while indomethacin or SC-560 promoted similar enhancing actions (38\% and 41\%) (fig 6I, L, O, R; fig 7C).

Carbachol $(1 \mu \mathrm{M})$ was tested on colonic preparations from COX-2 knockout mice and elicited atropine sensitive contractions (fig 8A). These responses did not vary significantly following incubation with indomethacin (fig 8B, C), SC-560, DFU, or coincubation with SC-560 plus DFU (fig 8C).

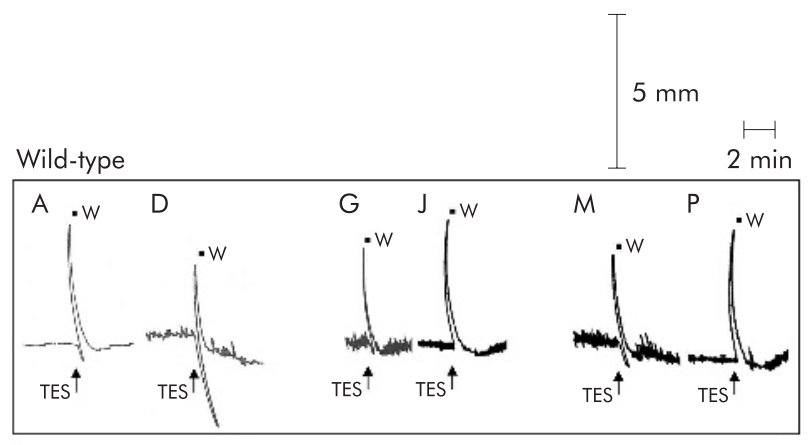

COX-1 knockout

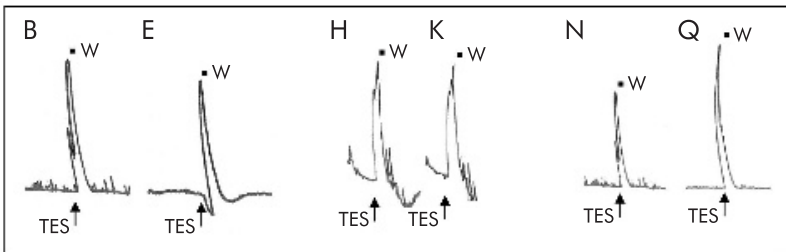

\section{COX-2 knockout}

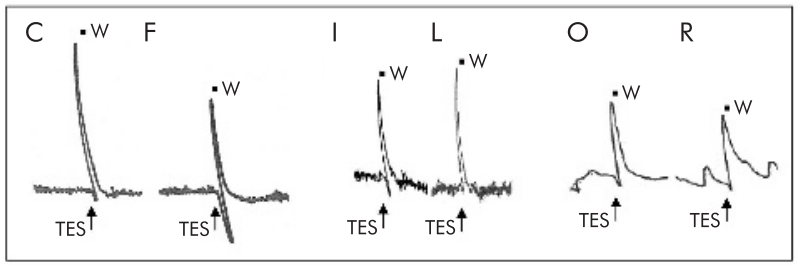

Figure 6 Distal colon isolated from wild-type (upper panel), cyclooxygenase 1 (COX-1) knockout (middle panel), or cyclooxygenase 2 (COX-2) knockout (lower panel) mice. Representative trace recordings showing the contractile responses of longitudinal muscle to application of transmural electrical stimulation (TES $0.5 \mathrm{~ms}, 10 \mathrm{~Hz}, 10$ seconds), alone $(A-C, G-I, M-O)$ or in the presence of atropine $1 \mu M(D-F)$, SC-560 $0.1 \mu \mathrm{M}(\mathrm{J}-\mathrm{L})$, or DFU $1 \mu \mathrm{M}(\mathrm{P}-\mathrm{R})$.
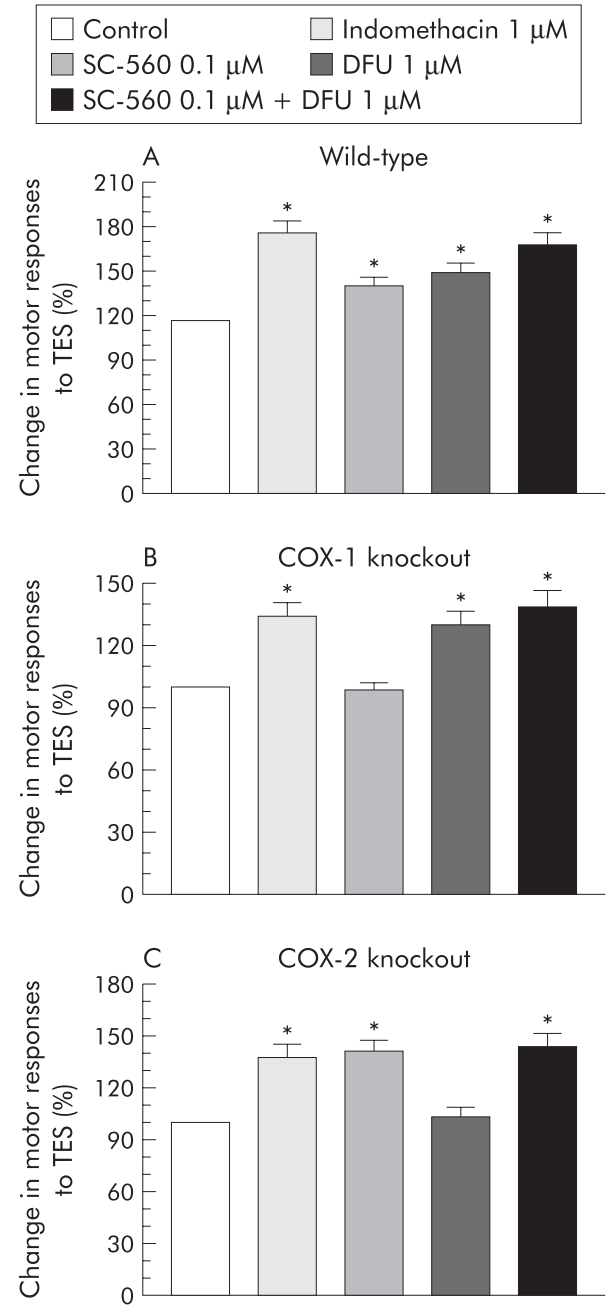

Figure 7 Distal colon isolated from wild-type (A), cyclooxygenase 1 (COX-1) knockout (B), or cyclooxygenase 2 (COX-2) knockout mice (C). Effects of indomethacin $1 \mu \mathrm{M}, \mathrm{SC}-5600.1 \mu \mathrm{M}$, DFU $1 \mu \mathrm{M}$, or SC-560 plus DFU on the contractile responses of longitudinal muscle to application of transmural electrical stimulation (TES $0.5 \mathrm{~ms}, 10 \mathrm{~Hz}$, 10 seconds). Each column represents the mean (SEM) value obtained from 5-7 experiments. ${ }^{*} p<0.05$ compared with control value.

\section{DISCUSSION}

Following the discovery of COX-1 and COX-2, it has become increasingly evident that COX-2 is constitutively expressed in various tissues where this enzyme mediates important regulatory actions. ${ }^{26}$ At the gastrointestinal level, marked COX-2 induction has been described within the mucosa in the presence of inflammation or ulcers, ${ }^{56}$ and COX-2 expression has been reported within neuromuscular compartments, mainly in association with inflammation. ${ }^{15}{ }^{16}$ On this basis, we attempted to characterise the expression and functional relevance of cyclooxygenase isoforms in the neuromuscular layer of the normal human colon. Evidence was indeed obtained that COX-1 and COX-2 are constitutively expressed in colonic tunica muscularis, and that both contribute in modulating the cholinergic control of motor activity at the neuronal and muscular levels.

Prior to addressing the consequences of pharmacological manipulations on contractile activity, we examined expression and cellular localisation of COX-1 and COX-2 in target tissues. RT-PCR analysis of human colonic muscle revealed expression of mRNA encoding both cyclooxygenase isoforms. The same observation was made in samples from wild-type 

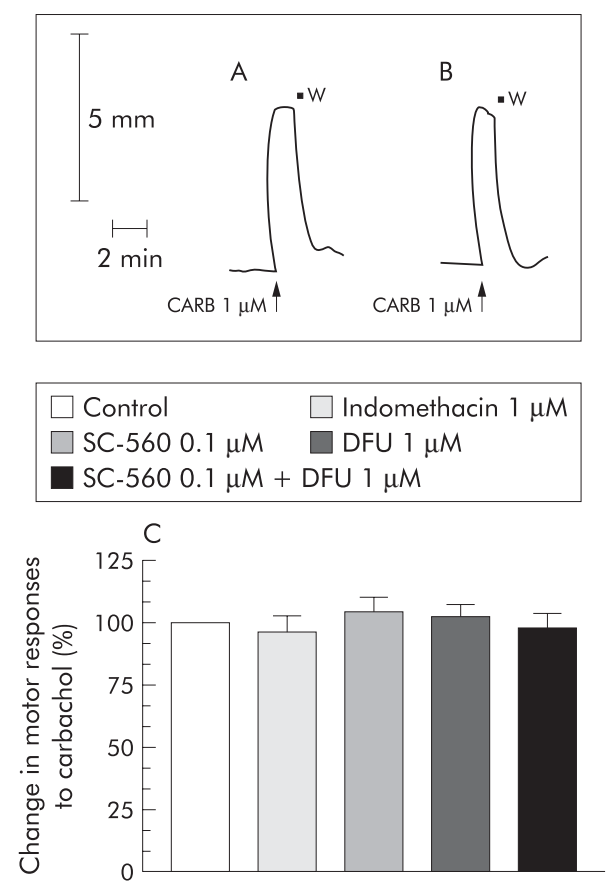

Figure 8 Distal colon isolated from cyclooxygenase 2 (COX-2) knockout mice. Upper panel: representative trace recording showing the effects of carbachol (CARB $1 \mu \mathrm{M})$, alone (A) or in the presence of indomethacin $1 \mu \mathrm{M}(\mathrm{B})$, on the contractile activity of longitudinal muscle preparations incubated in medium containing tetrodotoxin $1 \mu \mathrm{M}$. W, washing. Lower panel (C): column graph displaying the effects of indomethacin $1 \mu \mathrm{M}, \mathrm{SC}-5600.1 \mu \mathrm{M}$, DFU $1 \mu \mathrm{M}$, or SC-560 plus DFU on the contractile responses of longitudinal muscle preparations elicited by carbachol $1 \mu \mathrm{M}$ in the presence of tetrodotoxin $1 \mu \mathrm{M}$. Each column represents the mean (SEM) value obtained from 5-6 experiments.

mice and, as expected, COX-1 or COX-2 mRNA was not detected in COX-2 or COX-1 knockout mice. Of note, COX-1 and COX-2 expression did not vary at different experimental times, indicating that tissue manipulation did not affect gene transcription. Immunohistochemical analysis of human colon confirmed the RT-PCR data and demonstrated expression of cyclooxygenase proteins in different cellular sites: both COX-1 and COX-2 were detected in neurones of the myenteric ganglia, COX-1 was predominantly expressed in circular layer myocytes, and COX-2 immunopositivity was evident in longitudinal muscle. Taken together, these findings add novel evidence to the concept that COX-2 can be expressed constitutively in normal gut tissues. Indeed, previous studies reported the constitutive expression of COX-2 in healthy digestive mucosa, ${ }^{327}$ and constitutive COX-2 was detected in the tunica muscularis of normal rodent gut. ${ }^{12} 1316$

When applied to human colonic preparations, cyclooxygenase inhibitors enhanced electrically induced atropine sensitive contractions of longitudinal muscle. This potentiating action was already evident in the absence of other pharmacological treatments but was better appreciated on pharmacological suppression of non-cholinergic pathways. In these settings, significant enhancement of evoked cholinergic contractions was observed following COX-1 (SC-560) or COX-2 (DFU) blockade, and most prominent effects were recorded with SC-560 plus DFU or indomethacin alone.

As cyclooxygenase inhibitors may have affected cholinergic responses of human colon at neuronal and/or muscular sites, their effects were examined during exogenous activation of muscarinic receptors on longitudinal muscle, and clear evidence was obtained that carbachol induced contractions were enhanced following COX-2, but not COX-1, inhibition.
Of note, the specificity of such actions was substantiated by showing that histamine induced myogenic contractions were not modified by cyclooxygenase blockade. Furthermore, the enhancing effects of cyclooxygenase inhibitors are unlikely to depend on variations in muscle tone as no significant changes in resting tone were observed when incubating colonic preparations with SC-560, DFU or, in most cases, indomethacin. Although in a previous study indomethacin enhanced the contractile responses of human small intestine longitudinal muscle to electrical stimulation or acetylcholine, and such effects were proposed to result from concomitant reductions in muscle tone, ${ }^{28}$ it should be acknowledged that the response patterns of intestinal muscle to cyclooxygenase products may vary considerably with the species, gut region, and muscle layer. Moreover, in line with our observations, indomethacin had no effect on basal tone but increased the response to acetylcholine when assayed on cat ileal smooth muscle. ${ }^{29}$ Overall, our present findings support the concept that: (a) in human colon, cyclooxygenases are involved in enteric circuitries exerting tonic inhibitory control on smooth muscle responses to endogenous acetylcholine; (b) both cyclooxygenase isoforms contribute to these regulatory actions; and (c) cholinergic neurones are mostly modulated by COX-1 activity while COX-2 acts mainly at the muscular level to downregulate muscarinic responses. Our experiments also suggest that COX-1 products may operate at the prejunctional level to modulate acetylcholine release whereas, since suprathreshold stimuli were applied to colonic preparations, a possible influence of COX-1 derived prostanoids on the excitability of cholinergic nerves could not be determined.

The motor patterns of preparations from wild-type mice compare favourably with those of human colon, as murine tissues responded to electrical stimuli with atropine sensitive contractions which were enhanced by indomethacin, SC-560, or DFU. Furthermore, data from COX-1 or COX-2 deficient mice confirmed that SC-560 and DFU affected colonic motility via specific interactions with cyclooxygenase isoforms, and strongly support the implication of both cyclooxygenases in the control of gut neuromuscular functions. For a correct interpretation of the data obtained from cyclooxygenase deficient mice, it is important to mention that control evoked contractions of colonic preparations from knockout mice did not differ significantly from those recorded in wild-type animals. Although one might expect that knockout mice display enhanced contractile responses to electrical stimulation, compared with wild type animals, here we present evidence that COX-1 and COX-2 operate at different levels to regulate the activity of myenteric pathways driving colonic motor functions. Therefore, it is conceivable that, following genetic suppression of one cyclooxygenase enzyme, the other isoform can ensure sufficient physiological modulation of gut motor activity. In keeping with this view, gastric fundus muscles, isolated from COX-2 knockout or wild-type mice, responded in a similar manner to relaxant stimuli, while displaying different sensitivities to the effects of indomethacin or selective COX-2 blockade. ${ }^{12}$

The observation that both cyclooxygenase isoforms cooperate to modulate cholinergic control of human colonic motility represents a novel aspect of this study, as much attention is being currently directed to the role of COX-2 in enteric neuromotility during inflammation. ${ }^{16}{ }^{30}$ Some lines of evidence concur with the present results to suggest that cyclooxygenase products can affect myenteric cholinergic neurotransmission and/or muscarinic mediated contractile activity in normal digestive tissues, with different mechanisms and functional consequences depending on the gut region and species examined. De Backer and colleagues ${ }^{31}$ observed that indomethacin enhanced electrically induced 
acetylcholine release from smooth muscle strips of pig stomach suggesting, in line with our data, an inhibitory action of endogenous prostanoids on intramural cholinergic neurones. In contrast, studies on longitudinal muscle of guinea pig ileum showed that electrically or nicotine induced acetylcholine release, and related cholinergic contractions, can be stimulated by prostaglandins and reduced by indomethacin, indicating that endogenous prostanoids mediate the excitatory effect in this model..$^{32}{ }^{33}$ Pharmacological concentrations of prostaglandins contract the longitudinal muscle of human stomach and distal colon while prostacyclin induces relaxant responses and counteracts the contractile activity being elicited by exogenous acetylcholine. ${ }^{34} 35$ Although little is known of the influence of endogenous prostanoids on human digestive muscle, Porcher and colleagues $^{12}$ reported that phasic contractions of mouse gastric muscle, being induced by exogenous acetylcholine, are enhanced by indomethacin or GR253035X, a selective COX-2 inhibitor. These findings agree fully with our results, showing that carbachol induced contractile responses in human preparations were enhanced following COX-2, but not COX-1, blockade. In addition, the present data from colonic preparations of COX-2 deficient mice, showing that carbachol induced contractions were not affected by any cyclooxygenase inhibitor, further support the view that COX-2 operates directly on smooth muscle to modulate cholinergic motor activity.

Cellular locations of cyclooxygenase isoforms, as evidenced by immunohistochemistry, are compatible with present pharmacological data, as COX-1 expression in myenteric ganglia may subserve a role in modulation of cholinergic neurotransmission and COX-2 within longitudinal muscle may explain the enhancing effect of DFU on carbachol induced contractions. At the same time, the fact that COX-2 was not detected in the circular muscle layer is consistent with the observation that carbachol induced contractions of human colonic circular muscle are not significantly affected by incubation with indomethacin or DFU (Blandizzi, unpublished results). Of interest, our immunohistochemical results are partly consistent with the data of Porcher and colleagues ${ }^{12}$ who identified constitutive expression of COX-2 in myenteric neurones of mouse stomach. They did not perform immunohistochemistry for COX-1 and, despite positivity of RT-PCR for COX-1 and COX-2, they could not detect COX-2 immunoreactivity in smooth muscle cells. However, differences in species and gut regions may account for differential expression patterns of cyclooxygenase isoforms in digestive tissues. For instance, Barbara and colleagues ${ }^{16}$ demonstrated COX-2 expression within circular muscle in normal rat jejunum. Moreover, the functional significance of COX-1 expression in circular muscle and COX-2 in myenteric ganglia of human colon remains to be examined. Previous reports showed that indomethacin reduced electrically induced after contractions in longitudinal muscle of human small intestine or mouse colon, ${ }^{28}{ }^{36}$ raising the interesting possibility that endogenous prostanoids contribute to facilitate the activity of excitatory non-cholinergic pathways. Although our study focused on the influence of cyclooxygenase isoforms on cholinergic motility, the present findings, together with previous studies, ${ }^{28} 296$ indicate that the cyclooxygenase enzymes are involved in a complex regulatory network of intestinal neuromuscular functions, and that further investigations are required to clarify the relationships between cyclooxygenase isoforms and non-cholinergic enteric pathways. It also remains to be examined whether cyclooxygenase enzymes are expressed in interstitial cells of Cajal and/or regulate any activity of these cells at the human gut level. Indeed, Cajal cells have been implicated in the control of enteric motor neurotransmission ${ }^{37}$ and were recently shown to express COX-2 in mouse stomach, ${ }^{12}$ suggesting that these cells may represent an important site of prostanoid production within digestive muscle layers. We are currently addressing this issue and, consistently with data reported by Porcher and colleagues, ${ }^{12}$ our preliminary immunohistochemical evidence indicates that, on labelling with c-Kit antiserum, ${ }^{38}$ a proportion of Cajal cells do express COX-2 in the normal human colon (Bernardini, unpublished results).

In conclusion, the present results indicate that both COX-1 and COX-2 are expressed in the neuromuscular compartment of the human distal colon, and suggest that these isoforms, acting respectively at prejunctional and postjunctional sites, contribute to local inhibitory networks thought to modulate the excitatory control of colonic motility driven by myenteric cholinergic pathways. These findings can provide a basis to interpret the regulatory actions of prostanoids and cyclooxygenase inhibitors on intestinal motility under either normal or pathological conditions.

\section{ACKNOWLEDGEMENTS}

We thank Professor Flavio Coceani (Scuola Superiore S Anna and Institute of Clinical Physiology, National Research Council, Pisa, Italy) for his expert and critic review of the manuscript. The present work was supported by a grant from the Italian Ministry of Education, University and Research (COFIN 2002, project number 2002052573-003).

\section{Authors' affiliations}

M Fornai, C Blandizzi, R Colucci, L Antonioli, M Del Tacca, Division of Pharmacology and Chemotherapy, Department of Oncology,

Transplants and Advanced Technologies in Medicine, University of Pisa, Pisa, Italy

N Bernardini, C Segnani, Section of Histology, Department of Human Morphology and Applied Biology, University of Pisa, Pisa, Italy

B Baragatti, S Barogi, Laboratory of Physiological Genomics, Scuola Superiore S Anna and Institute of Clinical Physiology, National Research Council, Pisa, Italy

P Berti, R Spisni, Department of Surgery, University of Pisa, Pisa, Italy

Conflict of interest: None declared.

\section{REFERENCES}

1 O'Neill GP, Ford-Hutchinson AW. Expression of mRNA for cyclooxygenase- 1 and cyclooxygenase-2 in human tissues. FEBS Lett 1993;330:156-60.

2 Vane JR, Bakhle YS, Botting RM. Cyclooxygenases 1 and 2. Annu Rev Pharmacol Toxicol 1998;38:97-120.

3 MacNaughton WK, Cushing K. Role of constitutive cyclooxygenase-2 in prostaglandin-dependent secretion in mouse colon in vitro. J Pharmacol Exp Ther 2000;293:539-44.

4 Eberhart CE, DuBois RN. Eicosanoids and the gastrointestinal tract. Gastroenterology 1995;109:285-301.

5 Singer II, Kawka DW, Schloemann S, et al. Cyclooxygenase 2 is induced in colonic epithelial cells in inflammatory bowel disease. Gastroenterology 1998; 115:297-306

6 Halter F, Tarnawski AS, Schmassmann A, et al. Cyclooxygenase 2implications on maintenance of gastric mucosal integrity and ulcer healing: controversial issues and perspectives. Gut 2001;49:443-53.

7 Subbaramaiah K, Dannenberg AJ. Cyclooxygenase 2: a molecular target for cancer prevention and treatment. Trends Pharmacol Sci 2003;24:96-102.

8 Warner TD, Giuliano F, Vojnovic I, et al. Nonsteroid drug selectivities for cyclo-oxygenase- 1 rather than cyclo-oxygenase-2 are associated with human gastrointestinal toxicity: a full in vitro analysis. Proc Natl Acad Sci U S A 1999;96:7563-8

9 Wallace JL, McKnight W, Reuter BK, et al. NSAID-induced gastric damage in rats: requirement for inhibition of both cyclooxygenase 1 and 2 . Gastroenterology 2000;119:706-14

10 Northey A, Denis D, Cirino M, et al. Cellular distribution of prostanoid EP receptors mRNA in the rat gastrointestinal tract. Prostaglandin Other Lipid Mediat 2000;62:145-56.

11 Manning BP, Sharkey KA, Mawe GM. Effects of $\mathrm{PGE}_{2}$ in guinea pig colonic myenteric ganglia. Am J Physiol (Gastrointest Liver Physiol) 2002;283:G1388-97.

12 Porcher C, Horowitz B, Bayguinov O, et al. Constitutive expression and function of cyclooxygenase-2 in murine gastric muscles. Gastroenterology 2002;122:1442-54.

13 Schwarz NT, Kalff JC, Turler A, et al. Prostanoid production via COX-2 as a causative mechanism of rodent postoperative ileus. Gastroenterology $2001 ; 121: 1354-71$. 
14 Kallf JC, Turler A, Schwarz NT, et al. Intra-abdominal activation of a local inflammatory response within the human muscularis externa during laparotomy. Ann Surg 2003;237:301-15.

15 Roberts PJ, Morgan K, Miller R, et al. Neuronal COX-2 expression in human myenteric plexus in active inflammatory bowel disease. Gut 2001·48:468-72.

16 Barbara G, De Giorgio R, Deng Y, et al. Role of immunological factors and cyclooxygenase- 2 in persistent postinfective enteric muscle dysfunction in mice. Gastroenterology 2001;120:1729-36.

17 Blandizzi C, De Paolis B, Colucci R, et al. Characterization of a novel mechanism accounting for the adverse cholinergic effects of the anticancer drug irinotecan. Br J Pharmacol 2001;132:73-84.

18 Morham SG, Langenbach R, Loftin CD, et al. Prostaglandin synthase 2 gene disruption causes severe renal pathology in the mouse. Cell 1995;83:473-82.

19 Baragatti B, Brizzi F, Ackerley C, et al. Cyclooxygenase-1 and cyclooxygenase- 2 in the mouse ductus arteriosus: individual activity and functional coupling with nitric oxide synthase. Br J Pharmacol 2003;139:1505-15.

20 Hla T, Neilson K. Human cyclooxygenase-2 cDNA. Proc Natl Acad Sci U S A 1992:89:7384-8.

21 Ballou LR, Botting RM, Goorha S, et al. Nociception in cyclooxygenase isozyme-deficient mice. Proc Natl Acad Sci U S A 2000;97:10272-6.

22 Bernardini N, Bianchi F, Dolfi A. Laminin and betal integrin distribution in the early stages of human kidney development. Nephron 1999;81:289-95.

23 Riendeau D, Percival MD, Boyce S, et al. Biochemical and pharmacological profile of a tetrasubstituted furanone as a highly selective COX-2 inhibitor. Br J Pharmacol 1997;121:105-17

24 Kato M, Nishida S, Kitasato H, et al. Cyclooxygenase- 1 and cyclooxygenase2 selectivity of non-steroidal anti-inflammatory drugs: investigation using human peripheral monocytes. J Pharm Pharmacol 2001;53:1679-85.

25 Maggi CA, Giuliani S. Role of tachykinins as excitatory mediators of NANC contraction in the circular muscle of rat small intestine. J Autonom Pharmacol 1995: 15:335-50.

26 DuBois RN, Abramson SB, Crofford L. Cyclooxygenase in biology and disease. FASEB J 1998;12:1063-73.
27 Zimmerman KC, Sarbia M, Schror K, et al. Constitutive cyclo-oxygenase-2 expression in healthy human and rabbit gastric mucosa. Mol Pharmacol 1998;54:536-40

28 Bennett A, Stockley HL. The contribution of prostaglandins in the muscle of human isolated small intestine to neurogenic responses. Br J Pharmacol 1977;61:573-8.

29 Sanders KM. Endogenous prostaglandin E and contractile activity of isolated ileal smooth muscle. Am J Physiol 1978;234:E209-12.

30 Linden DR, Sharkey KA, Ho W, et al. Cyclooxygenase-2 contributes to dysmotility and enhanced excitability of myenteric $\mathrm{AH}$ neurones in the inflamed guinea pig distal colon. J Physiol 2004;557:1, 191-205.

31 De Backer O, Leclere PG, Lefebvre RA. Pharmacological characterization of pre- and postsynaptic prostanoid receptors in pig gastric fundus. Neuropharmacology 2003;45:684-90.

32 Bennett A, Kenneth GE, Stockley HL. Modulation by prostaglandins of contractions in guinea-pig ileum. Prostaglandins 1975:9:377-84.

33 Takeuchi T, Okuda M, Yagasaki $O$. The differential contribution of endogenous prostaglandins to the release of acetylcholine from myenteric plexus of the guinea-pig ileum. Br J Pharmacol 1991;102:381-5.

34 Bennett A, Hensby CN, Sanger GJ, et al. Metabolites of arachidonic acid formed by human gastrointestinal tissues and their actions on the muscle layers. Br J Pharmacol 1981;74:435-44.

35 Percy WH, Burton MB, Fallick F, et al. A comparison in vitro of human and rabbit distal colonic muscle responses to inflammatory mediators. Gastroenterology 1990;99:1324-32.

36 Fontaine J, Grivegnee A, Reuse J. Adrenoceptors and regulation of intestinal tone in the isolated colon of the mouse. Br J Pharmacol 1984;81:231-43.

37 Ward SM, Beckett EA, Wang X, et al. Interstitial cells of Cajal mediate cholinergic neurotransmission from enteric motor neurons. J Neurosci 2000;20:1393-403.

38 Fintl C, Pearson GT, Ricketts SW, et al. The development and distribution of the interstitial cells of Cajal in the intestine of the equine fetus and neonate. J Anatomy 2004;205:35-44.

\section{EDITOR'S QUIZ: GI SNAPSHOT}

\section{An unusual case of terminal ileal stricture}

\section{Clinical presentation}

A 42 year old unemployed male was referred to the gastroenterology department for investigation of constant severe abdominal pain and profound weight loss (45 kg over an eight month period). Further questioning revealed intermittent diarrhoea, steatorrhoea, and rectal bleeding. He was a smoker of 60 cigarettes per day but denied alcohol excess.

Examination revealed a cachectic man but no specific positive findings were revealed on systems examination.

Endoscopy with distal duodenal biopsy, pancrealauryl test, and plain computed tomography of the abdomen were all normal. Colonoscopy revealed normal colonic mucosa.

\section{Question}

A view of the terminal ileum is shown in fig l; describe the appearance and the most likely diagnosis(es).

See page 653 for answer

This case is submitted by:

D R Gaya, A J Morris

Department of Gastroenterology, Glasgow Royal Infirmary, Glasgow, UK J J Going

Department of Pathology, Glasgow Royal Infirmary, Glasgow, UK

Correspondence to: Dr D Gaya, Department of Gastroenterology, Wards 8 and 9, Glasgow Royal Infirmary, Castle St, Glasgow G4 OSF, UK danielgaya@aol.com

doi: $10.1136 /$ gut.2004.048769
Robin Spiller, Editor

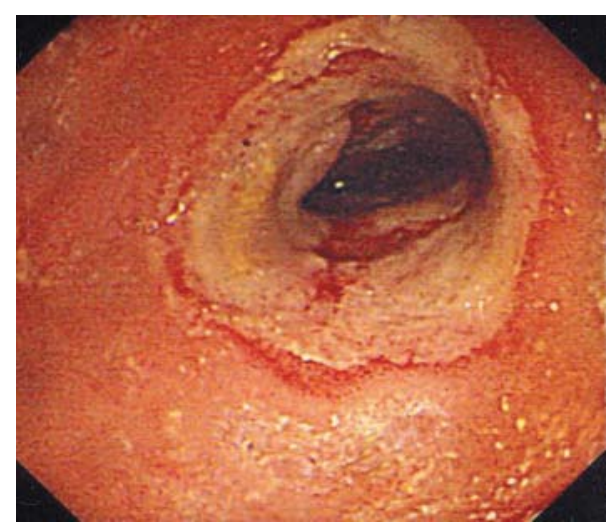

Figure 1 A view of the terminal ileum. 